九州大学学術情報リポジトリ

Kyushu University Institutional Repository

\title{
Anti-feeding and Insecticidal Activities of Extracts from Seven Wild Herbs against Diamondback Moth (Plutella xylostella)
}

Yang, Shang-Dong

College of Agriculture, Guangxi University

Zhao, Tian-Yi

College of Agriculture, Guangxi University

Li, Cai-Yuan

College of Agriculture, Guangxi University

Lan, Yan-Ni

College of Agriculture, Guangxi University

他

https://doi.org/10.5109/10085

出版情報: 九州大学大学院農学研究院紀要. 53 (1)，pp.143-148，2008-02-28. Faculty of Agriculture, Kyushu University

バージョン：

権利関係 : 


\title{
Anti-feeding and Insecticidal Activities of Extracts from Seven Wild Herbs against Diamondback Moth (Plutella xylostella)
}

\author{
Shang-Dong YANG ${ }^{1}$, Tian-Yi ZHAO ${ }^{1}$, Cai-Yuan LI $^{1}$, Yan-Ni LAN ${ }^{1}$ \\ and Kazuhiko EGASHIRA*
}

\author{
Laboratory of Soil Science, Division of Soil Science and Plant Production, \\ Department of Plant Resources, Faculty of Agriculture, \\ Kyushu University, Fukuoka 812-8581, Japan \\ (Received November 9, 2007 and accepted November 30, 2007)
}

\begin{abstract}
Seven kinds of most popularly used as medical herb in Guangxi Province, China were tested on the inhibition of a harmful insect, diamondback moth (Plutella xylostella). In addition to the inhibiting effect of herb extracts on the growth and development of diamondback moth, the anti-feeding and insecticidal activities against it were assessed. The extract from wild crowndaisy chrysanthemum (Chrysanthemum coronatium) was found to be most effective among the seven herbs. The 4-time diluted water extract of wild crowndaisy chrysanthemum showed the similar effect as the 1000-time diluted solution of 50\% phoxim at five days after application, and was proposed as a prospective bio-pesticide to replace it.
\end{abstract}

\section{INTRODUCTION}

In recent years, chemical pesticides have been more popularly used as necessary goods in the modern agriculture. Although it has contributed to preventing pests and improving the crops yield, the long-term use of chemical pesticides has induced serious impact on the environment, such as loss of biodiversity, increased resistance of pests against pesticides and risk to the human health, and so on. For these reasons, use of chemical pesticide is getting to be controlled strictly in every country. Furthermore, laws concerning inhibition of use of some chemical pesticides have been issued in some advanced countries

In China, bio-pesticides have been used from ancient time. According to the introductory paper (Yang et al., 2006), some medical herbs had been used in crop production 2000 years ago for prevention from pests. Bio-pesticides were extracted from herbs that could be eaten or used as a medical purpose, and have been used without a harmful effect on human being and livestock or with the marginal, if any, influence on them. Herbs are grown in nature and can be biodegraded without exerting any adverse effect on the environment. In addition, bio-pesticides are composed of complex components, while chemical pesticides are usually consisted of a simple component. For this reason, it is stated that the increased resistance of pests against pesticides can be avoided in case of bio-pesticides.

Guangxi Zhuang Autonomous Province (abbreviated as Guangxi Province thereafter) is located in the southwestern part of China. It belongs to the typical subtropical zone and is rich in herb resources. According to the book of «Guangxi Comprehensive History»

\footnotetext{
1 Laboratory of Horticulture Science, Division of Horticulture Science and Plant Production, College of Agriculture, Guangxi University, Nanning, Guangxi Province, China 53004; E-mail address of the top author: yangshangdong@hotmail.com

* Corresponding author (E-mail: kegashi@agr.kyushu-u.ac.jp)
}

(Committtee of Guangxi Comprehensive History, 1994), there are 7,000 kinds of medical herbs in China and 4,064 kinds in Guangxi, equivalent to $58.1 \%$ of the country. According to another book of $\ll$ Local Bio-Pesticides in China》 (Committee of Local Bio-Pesticides in China, 1959), it is described that there are nearly 220 kinds of bio-pesticides in China and more than 100 kinds of them in Guangxi. It has been suggested that Guangxi has favorable conditions for developing production and use of bio-pesticides (Huang, 2002).

Diamondback moth (Plutella xylostella) is one of the major pests all over the world. It mainly damages vegetables of the mustard family, such as cabbage, rape, etc. Diamondback moth is distributed in the whole country of China, but the damage is more serious from the area along the Yangzi River to the southern region (Li, 2002). Prevention and control of diamondback moth has been mainly done by application of chemical pesticides, secondarily with the ways of crop rotation, intercropping and bio-prevention. However, through the long-term application of chemical pesticides, the pesticide-resistant ability of diamondback moth was getting stronger.

For example, diamondback moth showed the resistant ability against the six kinds of pesticides used in the modern agriculture in the following sequence: pyrethroid $>$ carbamate $>$ acyl-urea $>$ organic phosphorous insecticide $>$ Bt $>$ nereistoxin (Wang et al., 1993). As a result, with the increased ability of diamondback moth in the pesticide-resistance, farmers had to spray that chemical pesticide with a higher concentration than usual or shortening of a spraying interval. It easily leads to the environmental pollution and food poisoning.

The objective of the present study was to select out some herbs with the controlling effect on diamondback moth from seven wild herbs which can be collected easily. The controlling effect was examined by the laboratory test and the field experiment. 


\section{MATERIALS AND METHODS}

\section{Test pest and its breeding}

Adult diamondback moths were captured in the farm of the College of Agricultural, Guangxi University, during April and October 2004, and then bred in the laboratory according to the method of Qin et al. (2004). The conditions of breeding were set up as follows: temperature, $25 \pm 1{ }^{\circ} \mathrm{C}$; humidity, 65 75\%; light intensity, 1,000 4,000 lux; time of illumination, 14 16 hours per day. In breeding, diamondback moths in a breeding box were fed with leaves of mustard (Brassica alba) put on a dish. Mustard leaves were changed timely according to the situation of eating. At the same time, a cotton ball that had been immersed into the $10 \%$ glucose solution was placed near the dish to provide nutrients to diamondback moths. The cotton ball was changed every day. After adult diamondback moths laid eggs and hatched eggs were bred for a while, the 3rd instar larvae under the identical growth rate were used as the test pest.

\section{Test herbs and preparation of extracts}

Test herbs collected in the suburbs of Nanning City are listed in the following table. Families and test parts of the herbs are shown in Table 1.

(1) Chinese mugwort (Artemisia argyi)

(2) Oleander (Nerium indicum)

(3) Short-tube lycoris (Lycoris radiata)

(4) Crowndaisy chrysanthemum (Chrysanthemum coronatium)

(5) Peppermint (Mentha arvensis)

(6) Five-leaved chaste tree (Vitex negundo)

(7) Chinese wedelia herb or root (Wedelia chinensis)

Preparation of herb extract was based on the method of Luo (2000). The test part of the respective herbs was cut finely into pieces, immersed into the cooled boilingwater with a ratio of 1:3 of herb and water, and stirred constantly for 3 days. The mixture was filtered to get filtrate as a crude extract before test.

Chinese cabbage (Brassica pekinensis) (Zhao Shou No. 5) was used as diet of diamondback moth in the test.

\section{Laboratory test on the bioactivity of herb extracts}

The inhibiting effect on the growth and development of diamondback moth

The test was carried out according to the 'breeding method' described by Zhang et al. (2001). The fresh leaf of Chinese cabbage was dipped into the herb crude extract for 5 seconds, dried naturally under room temperature, and put on a culture dish. After that, the treated leaf placed on the dish was subjected to feeding by the 3rd instar larvae of diamondback moth given nothing to eat for 5 hours. Twenty-four hours later, the treated leaf was changed with the fresh leaf without dipping into the herb crude extract, and feeding by diamondback moths was continued under room temperature of $22.3 \sim 23.1^{\circ} \mathrm{C}$. The growth status of diamondback moths was observed and recorded. The test was repeated ten times.

The anti-feeding activity

The test was carried out according to the 'dish method' described by Qin et al. (2004). Fresh leaves of Chinese cabbage were cut into many circles of a $2.0-\mathrm{cm}$ diameter by a borer. The circular leaf pieces were dipped into the herb crude extract for 5 seconds, dried naturally under room temperature, and put on a culture dish on which a wet filter paper was placed. The circular leaf pieces were subjected to feeding by the 3rd instar larvae of diamondback moth given nothing to eat for 5 hours in an incubation box controlled at $28^{\circ} \mathrm{C}$.

Five head of the 3rd instar larva and 6 pieces of circular leaf were laid together on each dish in a test, and the test was repeated ten times for one herb crude extract. Dipping into distilled water instead of the herb extract was tested as the control. The area of a leaf piece eaten by diamondback moths was measured after 48 hours of feeding and summed up. The anti-feeding activity of the herb extract was evaluated by the antifeeding rate calculated by the next formula.

Anti-feeding rate $(\%)=\{100$ (eaten area in the control eaten area in the herb extract)/(eaten area in the control)

\section{The insecticidal activity}

The test was carried out according to the 'soak method' described by Xie et al. (2004). Healthy and same-sized 3rd instar larvae of diamondback moth were picked out. After directly dipped into the herb crude extract for 5 seconds, larvae were wiped with a filter paper to remove excess extract, put on a culture dish on which a fresh leaf of Chinese cabbage was placed, and incubated in an incubation box controlled at $28^{\circ} \mathrm{C}$. The leaf was changed frequently with eaten status. The test was made in triplicate for one herb crude extract, and 10 head of larva was used in a test. Dead larvae were counted after 2 days of incubation, and the mortality and

Table 1. Families and test parts of herbs

\begin{tabular}{lll}
\hline Herb & Family & Test part \\
\hline Chinese mugwort (Artemisia argyi) & Compositae & Whole plant \\
Oleander (Nerium indicum) & Apocynaceae & Whole plant \\
Short-tube lycoris (Lycoris radiata) & Amaryllidaceae & Stem \\
Crowndaisy chrysanthemum (Chrysanthemum coronatium) & Compositae & Whole plant \\
Peppermint (Mentha arvensis) & Labiatae & Whole plant \\
Five-leaved chaste tree (Vitex negundo) & Verbenaceae & Whole plant \\
Chinese wedelia herb or root (Wedelia chinensis) & Compositae & Whole plant \\
\hline
\end{tabular}


the corrected mortality were calculated by the next formulae.

Mortality (\%)=100(number of dead larvae)/(number of test larvae)

Corrected mortality $(\%)=100$ (mortality in the herb extract - mortality in the control $) /(100$ - mortality in the control)

Field experiment on the controlling effect of the wild crowndaisy chrysanthemum extract on diamondback moth

The field experiment was carried out to examine the controlling effect of wild herbs on diamondback moth in April 2004 in the university field of the College of Agriculture, Guangxi University. April is the season of the most frequent occurrence of diamondback moth. Chinese cabbage as an attacked plant was planted in the middle of March and fertilized as usual. Since, in the laboratory test, the highest efficacy was found to wild crowndaisy chrysanthemum in the three parameters of bioactivity, it was selected as a representative of the wild herbs. The crude extract was obtained by squeezing out crowndaisy chrysanthemum.

The following treatments were set with a aim to save the extract of wild crowndaisy chrysanthemum, and spraying was done during 8 and 18 of April.

Treatment CK: spraying water on leaves of Chinese cabbage as control;

Treatment I : spraying the original crude extract on leaves of Chinese cabbage;

Treatment II : spraying the 2-time diluted crude extract on leaves of Chinese cabbage;

Treatment III : spraying the 4-time diluted crude extract on leaves of Chinese cabbage;

Treatment IV : spraying the 8-time diluted crude extract on leaves of Chinese cabbage;

Treatment V : spraying leaves of Chinese cabbage with $50 \%$ phoxim with 1,000-time dilution according to the instruction manual.

In the university field of the College of Agriculture, Guangxi University, fields framed by concrete are arranged, and one field has an area of $20 \mathrm{~m}^{2}$ ( $1 \mathrm{~m} \times 20 \mathrm{~m}$ ). One field framed by concrete was assigned to one treatment and separated to 3 plots to have 3 replications. One field had 60 individuals of Chinese cabbage and then one plot had 20 individuals.

In each treatment, spraying was done on both sides of leaves of Chinese cabbage by a handy machine until the condition just before dropping of the extract. The pesticide solution was sprayed at a rate of about $40 \mathrm{~kg} / 667 \mathrm{~m}^{2}$. When rain came after spraying, re-spraying was done in the same way immediately after stopping of rain.

Before spraying, 10 out of 20 Chinese cabbages in each plot were selected out at random with marking on them, and the number of scars eaten by diamondback moth on leaves was counted to see the number of scars before treatment. The number of scars on leaves was counted again in the same way to the 10 marked plants at 1,3 and 5 days after spraying. The controlling rate was calculated by the following formula described by $\mathrm{Xu}$ et al. (2003) and Li (2005). The data obtained at 5 days after spraying was subjected to the statistical analyses.

Controlling rate $(\%)=100$ (number of scars on leaves before treatment - number of scars on leaves after treatment)/(number of scars on leaves before treatment)

\section{Statistical analyses}

Statistical analyses were carried out by Duncan's SSR test.

\section{RESULTS AND DISCUSSION}

\section{The inhibiting effect on the growth and develop- ment of diamondback moth}

Table 2 shows the inhibiting effect of the herb extracts on the growth and development of diamondback moth. As shown in Table 2, the durations until turning into pupa from larva and until hatching of egg were only 3.5 and 2.5 days, respectively, in dipping into water as control. The corresponding durations were 5.0 and 4.5 days for wild crowndaisy chrysanthemum and prolonged by 1.5 and 2.0 days, respectively, indicating that dipping into the crude extract of wild crowndaisy chrysanthemum inhibited manifestly the growth and development of diamondback moth.

All 7 wild herbs showed the inhibiting effect on the growth and development of diamondback moth with the following decreasing effect: wild crowndaisy chrysanthemum $>$ short-tube lycoris $>$ five-leaved chaste tree $>$ oleander $>$ peppermint $>$ Chinese wedelia herb or root $>$ Chinese mugwort. The size of pupa was all getting small visually by the treatment with the herb extracts compared with the control. Moreover, some pupas were deformed by the herb-extract treatment. Zhu et al. (2006) reported that the crude extract from a herb of Periploca sepium induced inhibition against the growth and development of Pieris rapae, similar to our finding to diamondback moth.

Table 2. The inhibiting effect of the herb extracts on the growth and development of diamondback moth

\begin{tabular}{lcc}
\hline Herb & $\begin{array}{c}\text { Duration until } \\
\text { pupation } \\
\text { under } 22.3^{\circ} \mathrm{C} \\
\text { (days) }\end{array}$ & $\begin{array}{c}\text { Duration of egg } \\
\text { until hatching } \\
\text { under } 23.1^{\circ} \mathrm{C} \\
\text { (days) }\end{array}$ \\
\hline Water as control & 3.5 & 2.5 \\
Chinese mugwort & 3.5 & 3.0 \\
Oleander & 4.0 & 3.5 \\
Short-tube lycoris & 4.5 & 3.0 \\
Crowndaisy chrysanthemum & 5.0 & 4.5 \\
Peppermint & 4.0 & 2.5 \\
Five-leaved chaste tree & 4.5 & 3.5 \\
Chinese wedelia herb or root & 4.0 & 4.0 \\
\hline
\end{tabular}




\section{The anti-feeding activity against diamondback moth}

Table 3 shows the eaten area of Chinese cabbage dipped into water and herb extracts by the 3rd instar larva of diamondback moth and the anti-feeding rate of the herb extracts. As shown in Table 3, the average area eaten and the anti-feeding rate for the herb extracts were all significantly different at the $1 \%$ level from the control. The highest anti-feeding rate of $74.8 \%$ was obtained in the extract from wild crowndaisy chrysanthemum among the herbs examined. Next is short-tube lycoris with the rate of $72.9 \%$, not significantly different from wild crowndaisy chrysanthemum, and followed by Chinese mugwort and peppermint $>$ Chinese wedelia herb or root $>$ five-leaved chaste tree and oleander.

The difference in the anti-feeding activity among the herb extracts may be explained by that functional components in volatile compounds of herbs are different with one another, leading to the difference in the bioactive functions against diamondback moth. Another idea is that the solvent good for extraction may vary with functional components, though water was used in the present study. Identification of bioactive components in herb extracts and search for solvents good for extraction of them are worthy of the future study.

\section{The insecticidal activity against diamondback moth}

Table 4 shows the results of the test on the insecticidal activity of the herb extracts against diamondback moth. As understood from Table 4, the insecticidal activity of the herb extracts against the 3rd instar larva of diamondback moth was all significantly greater than that of the control at the 1 or $5 \%$ level. The corrected mortality was distributed mostly around 50\%, and it indicated that the insecticidal activity of the herb extracts against the 3rd instar larva of diamondback moth was all in the intermediate level.

Among the herb extracts examined, oleander had the greatest insecticidal activity with the corrected mortality of $55.9 \%$, and next is short-tube lycoris with the value of $48.0 \%$, followed by wild crowndaisy chrysanthemum (47.7\%), five-leaved chaste tree (46.7\%), Chinese mugwort (43.2\%), Chinese wedelia herb or root (40.9\%), and peppermint (32.3\%). However, there was observed no significant difference between the herbs at the $1 \%$ level.

As shown in the above, extracts form wild herbs showed the more or less strong bioactivity against diamondback moth in the laboratory test. In the next step, whether extracts from wild herbs exert the controlling effect on diamondback moth in the field or not is of practical concern. Then, field experiment was carried out with the herb extract and a chemical pesticide of phoxim. Based on the results of the laboratory test, wild crowndaisy chrysanthemum was selected as a bio-pesticide and was compared with a chemical pesticide, 50\% of phoxim, in the controlling effect against diamondback moth.

\section{Field experiment}

The results of the field experiment are given in Table 5. The number of pest scars is those counted for

Table 3. Eaten area of Chinese cabbage dipped into water and herb extracts by diamondback moth and the anti-feeding rate of the herb extracts

\begin{tabular}{lcccc}
\hline \multirow{2}{*}{ Herb } & $\begin{array}{c}\text { Eaten area } \\
\left(\mathrm{mm}^{2}\right)\end{array}$ & $\begin{array}{c}\text { Anti-feeding } \\
\text { rate (\%) }\end{array}$ & \multicolumn{2}{c}{ Statistical significance } \\
\cline { 4 - 5 } Water as control & 314 & & $5 \%$ level & 1\% level \\
Chinese mugwort & 97 & 69.0 & $\mathrm{f}$ & $\mathrm{E}$ \\
Oleander & 188 & 40.0 & $\mathrm{bc}$ & $\mathrm{B}$ \\
Short-tube lycoris & 85 & 72.9 & $\mathrm{e}$ & $\mathrm{D}$ \\
Crowndaisy chrysanthemum & 79 & 74.8 & $\mathrm{a}$ & $\mathrm{A}$ \\
Peppermint & 107 & 65.7 & $\mathrm{c}$ & $\mathrm{B}$ \\
Five-leaved chaste tree & 176 & 43.9 & $\mathrm{e}$ & $\mathrm{D}$ \\
Chinese wedelia herb or root & 148 & 52.9 & $\mathrm{~d}$ & $\mathrm{C}$ \\
\hline
\end{tabular}

Different alphabets mean statistical difference at the respective levels.

Table 4. Results of the test on the insecticidal activity of the herb extracts against diamondback moth

\begin{tabular}{|c|c|c|c|c|c|c|}
\hline \multirow{2}{*}{ Herb } & \multirow{2}{*}{$\begin{array}{l}\text { Number of } \\
\text { test larvae }\end{array}$} & \multirow{2}{*}{$\begin{array}{l}\text { Number of dead } \\
\text { larvae after } 48 \mathrm{~h}\end{array}$} & \multirow{2}{*}{$\begin{array}{l}\text { Mortality } \\
\text { (\%) }\end{array}$} & \multirow{2}{*}{$\begin{array}{l}\text { Corrected mortality } \\
\qquad(\%)\end{array}$} & \multicolumn{2}{|c|}{ Statistical significance } \\
\hline & & & & & $5 \%$ level & $1 \%$ level \\
\hline Water as control & 50 & 6 & 12.0 & & $\mathrm{c}$ & $\mathrm{B}$ \\
\hline Chinese mugwort & 50 & 25 & 50.0 & 43.2 & $a b$ & A \\
\hline Oleander & 49 & 30 & 61.2 & 55.9 & $\mathrm{a}$ & A \\
\hline Short-tube lycoris & 48 & 26 & 54.2 & 48.0 & $a b$ & A \\
\hline Crowndaisy chrysanthemum & 50 & 27 & 54.0 & 47.7 & $a b$ & $\mathrm{~A}$ \\
\hline Peppermint & 47 & 19 & 40.4 & 32.3 & $\mathrm{~b}$ & $\mathrm{AB}$ \\
\hline Five-leaved chaste tree & 49 & 26 & 53.1 & 46.7 & $\mathrm{a}$ & A \\
\hline Chinese wedelia herb or root & 50 & 24 & 48.0 & 40.9 & $a b$ & A \\
\hline
\end{tabular}

Different alphabets mean statistical difference at the respective levels. 
Table 5. Results of the field experiment on the contolling effect of the wild crowndaisy chrysanthemum extract with different dilutions and a chemical pesticide on diamondback moth

\begin{tabular}{|c|c|c|c|c|c|c|c|}
\hline \multirow[b]{2}{*}{ Treatment } & \multirow[b]{2}{*}{$\begin{array}{l}\text { Number of } \\
\text { pest scars } \\
\text { before treatment }\end{array}$} & \multicolumn{2}{|c|}{ One day after spraying } & \multicolumn{2}{|c|}{ Three days after spraying } & \multicolumn{2}{|c|}{ Five days after spraying } \\
\hline & & $\begin{array}{l}\text { Number of } \\
\text { pest scars }\end{array}$ & $\begin{array}{l}\text { Decreasing } \\
\text { rate } \\
(\%)\end{array}$ & $\begin{array}{l}\text { Number of } \\
\text { pest scars }\end{array}$ & $\begin{array}{l}\text { Decreasing } \\
\text { rate } \\
(\%)\end{array}$ & $\begin{array}{l}\text { Number of } \\
\text { pest scars }\end{array}$ & $\begin{array}{l}\text { Decreasing } \\
\text { rate } \\
(\%)\end{array}$ \\
\hline CK & 95 & 90 & 5.3 & 93 & 2.1 & 89 & 6.3 \\
\hline I & 91 & 55 & 39.6 & 36 & 60.4 & 24 & 73.6 \\
\hline II & 86 & 58 & 32.6 & 36 & 58.1 & 24 & 72.1 \\
\hline III & 90 & 62 & 31.1 & 50 & 44.4 & 31 & 65.6 \\
\hline $\mathrm{IV}$ & 81 & 58 & 28.4 & 44 & 45.7 & 37 & 54.3 \\
\hline $\mathrm{V}$ & 88 & 7 & 92.0 & 12 & 86.4 & 19 & 78.4 \\
\hline
\end{tabular}

10 individuals of Chinese cabbage and averaged for 3 plots. As shown in Table 5, the decreasing rates of the treatments with the wild crowndaisy chrysanthemum extract with different dilutions were all smaller than that of phoxim at any days after spraying. The decreasing rate was reduced with the increasing dilution of the wild crowndaisy chrysanthemum extract. The decreasing rate of the chemical pesticide of phoxim was $92.0 \%$ at 1 day after spraying but decreased to 86.4 and $78.4 \%$ at 3 and 5 days, respectively, after spraying. It suggests that the controlling effect of phoxim against diamondback moth was getting weaker as days passing from spraying.

The controlling effect of the wild crowndaisy chrysanthemum extract was considerably weaker than that of phoxim at 1 and 3 days after spraying, judged from the magnitude of the decreasing rate. However, it was getting greater as days passing from spraying, and at 5 days after spraying the controlling effect of the wild crowndaisy chrysanthemum extract reached the level similar to that of phoxim except the 8-time dilution. These results indicate that the wild crowndaisy chrysanthemum extract, different from phoxim, scarcely shows an immediate controlling effect against diamondback moth but slowly exerts its controlling effect as days passing. It is an important characteristic of the wild crowndaisy chrysanthemum extract in exerting its bioactivity.

Table 6 shows the statistical difference in the decreasing rate between the treatments at 5 days after spraying. Except the 8-time dilution of the wild crowndaisy chrysanthemum extract, all the treatments showed an insignificant difference with each other at the

Table 6. Statistical difference in the decreasing rate between the treatments at 5 days after spraying

\begin{tabular}{ccc}
\hline \multirow{2}{*}{ Treatment } & \multicolumn{2}{c}{ Statistical significance } \\
\cline { 2 - 3 } & $5 \%$ level & $1 \%$ level \\
\hline CK & & \\
I & $\mathrm{a}$ & $\mathrm{A}$ \\
II & $\mathrm{ab}$ & $\mathrm{A}$ \\
III & $\mathrm{b}$ & $\mathrm{A}$ \\
IV & $\mathrm{c}$ & $\mathrm{B}$ \\
V & $\mathrm{a}$ & $\mathrm{A}$ \\
\end{tabular}

Different alphabets mean statistical difference at the respective levels.
1\% level. The controlling effect of the wild crowndaisy chrysanthemum extract against diamondback moth was not significantly different until the 4-time dilution. It suggests that the 4-time diluted extract from wild crowndaisy chrysanthemum could be used as a bio-pesticide against diamondback moth in the Chinese cabbage field.

\section{CONCLUSIONS}

Seven kinds of medical herbs collected in Nanning, Guangxi were tested on the harmful pest of diamondback moth (Plutella xylostella). According to the inhibiting effect, and the anti-feeding and insecticidal activities against diamondback moth in the laboratory, the highest efficacy in the controlling effect on the pest was found to the wild crowndaisy chrysanthemum extract. The 4-time diluted water extract from wild crowndaisy chrysanthemum showed the similar controlling effect on diamondback moth to that of the 1,000-time diluted 50\% phoxim at 5 days after spraying in the Chinese cabbage field, and was concluded to be used as a bio-pesticide in future.

\section{REFERENCES}

Committee of Guangxi Comprehensive History 1994 Guangxi Comprehensive History. Jinming Publisher of Guangxi Province, Nanning (China) (in Chinese)

Committee of Local Bio-Pesticides in China 1959 Local BioPesticides in China. Science Publisher of China, Beijing (China) (in Chinese)

Huang, C. -H. 2002 Introduction to the resources of plant-originated pesticides in Guangxi. Guangxi Plant Protection, 15(2): 29-31 (in Chinese)

Li, Y. -R. 2002 Agricultural Entomology. Agricultural Press of China, Beijing (China) (in Chinese)

Li, X. -R. 2004 Control efficacy of 3 kinds of bio-pesticide against Plutella xylostella. Gansu Agricultural Science and Technology, 5: 47-48 (in Chinese)

Luo, B. -L. 2000 The application and protection of plant-originated pesticide. Journal of Hunan Forestry Science and Technology, 1: 59-63 (in Chinese)

Qin, W. -Q., Z. -Q. Peng and B. Ling 2004 Oviposition deterring and anti-feeding effect of extracts of 20 tropical plants on diamondback moth (Plutella xylostella). Chinese Journal of Tropical Crops, 1: 49-53 (in Chinese)

Wang, W. -Z., W. -P. Chen and S. -Q. Liang 1993 The anti-activities of Plutella xylostella to Bt in Guangzhou, ShenSen Area. Acta Phytophylacica Sinica, 3: 273-276 (in Chinese) 
Xie, H. -Y., H. -Y. Jiang and G. -P. Wang 2004 Insecticide activities of extracts from Acorus graminues rhizome against Mythimna separata Walker. Chinese Journal of Pesticides, 8: 367-369 (in Chinese)

Xu, W., Y. -B. Gao, H. Lu, L. -L. Chen and M. Liu 2003 Field trial of efficacy of several kinds of bio-pesticides against Plutella xylostella. Journal of Jilin Agricultural University, 25(1): 38-40 (in Chinese)

Yang, C. -L., S. -H. Jiang and H. -H. Xu 2006 Research progresses in plant-originated repellents. Plant Protection, 6: 4-9 (in Chinese)

Zhang, Y. -P., B. -Q. Huang, X. Chen and Y. -L. Wu 2001 The inhibition of Synedrella nodiflora L. Gaertn. leaf extracts against Pieris rapae. Chinese Vegetables, 6: 8-10 (in Chinese)

Zhu, J. -S., X. -W. Qiao, J. Wang and S. Qin 2006 Effects of the crude extracts from Periploca sepium Bunge on the bioactivity of imported cabbage worm, Pieris rapae. Chinese Journal of Eco-Agriculture, 1: 185-188 (in Chinese) 